\title{
The Effect of Celery Therapy and Abdominal Stretching Exercise on Pain Intensity in Adolescent with Dysmenorrhea at the Soppeng High School
}

\author{
Sri Rezkiani Kas ${ }^{1 *}$, Nur Nasry Noor ${ }^{1}$, Muh. Tahir Abdulllah ${ }^{2}$, Anwar Mallongi $^{3}$, Erniwati Ibrahim ${ }^{3}$ \\ ${ }^{1}$ Department of Epidemiology, Faculty of Public Health, Hasanuddin University, Makassar, Indonesia; ${ }^{2}$ Department of \\ Reproductive Health, Faculty of Public Health, Hasanuddin University, Makassar, Indonesia; ${ }^{3}$ Department of Environmental \\ Health, Faculty of Public Health, Hasanuddin University, Makassar, Indonesia
}

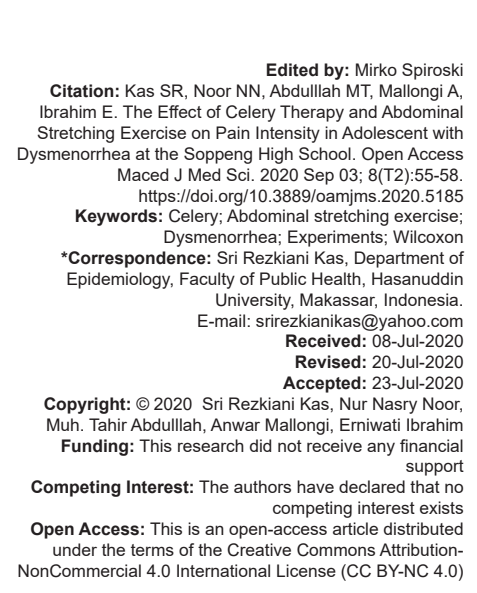

Introduction

Reproductive health is an important issue and needs to get more attention, especially among teenagers. Because adolescents are the next generation of the nation, adolescents should have excellent reproductive health because adolescents will later marry and become parents, so the quality of life of adolescents must improve in a better direction. Reproductive health is a mental, social, and physical condition that is not only free from disease or disability but everything that is related to the reproductive system itself both its function and process [1].

Based on data from the World Health Organization (WHO) in 2011, it was found that the incidence of women with dysmenorrhea was $1,769,425$ $(90 \%)$ and in 2012 , the incidence of dysmenorrhea in the world averaged more than about $50 \%$ of women in each state experiencing pain during menstruation.
In the United States, the incidence of dysmenorrhea is around $60 \%$ and in Sweden around $72 \%$, whereas in Indonesia, the incidence of dysmenorrhea is 107,673 people $(64.25 \%)$ consisting of 59,671 people $(54.89 \%)$ who have primary dysmenorrhea and 9496 people $(9.36 \%)$ who have secondary dysmenorrhea. Around $54.89 \%$ of primary dysmenorrhea occurrences occur in Indonesia while the rest are secondary dysmenorrhea in adolescents, while in East Java, the incidence of dysmenorrhea is $64.25 \%$ consisting of $54.89 \%$ primary dysmenorrhea and $9.36 \%$ secondary dysmenorrhea. Although considered harmless, dysmenorrhea can cause discomfort for women who experience it [2].

According to Daley [3], menstrual pain is pain that feels in the lower abdomen such as gripping or kneading, throbbing headaches, nausea, vomiting, pain in the lower back, diarrhea, and even fainting. Adolescence is marked by the emergence of the characteristics of primary sex and secondary sex which is influenced by the start of the working of the reproductive glands. The characteristics of primary sex 
are irritability, anxiety, feeling worried, and menstruation, while the characteristics of secondary sex where the hips grow wider and rounder, breasts enlarge, the skin becomes smoother.

Dysmenorrhea is classified into two parts, namely, (1) primary dysmenorrhea associated with previous ovulation and associated with uterine muscle contractions (myometrium) and prostaglandin secretion and (2) secondary dysmenorrhea caused by pathological problems in the pelvic cavity. There are several ways to eliminate or relieve menstrual pain, both pharmacologically and non-pharmacologically. Non-pharmacological management is safer to use without using drugs so it does not cause side effects [3].

Non-pharmacological methods used to relieve dysmenorrhea include compressing warm baths, massage, distraction, physical exercise or exercise, getting enough sleep, a low salt diet, and increasing the use of natural diuretics such as celery leaves. Exercise can overcome dysmenorrhea because exercise is safer used for physiological processes. This is supported by the results of Daley research [3] which states that to reduce pain during menstruation (primary dysmenorrhea), exercise is very effective.

Celery is one of the herbs that are often used to treat food and also as a medicinal plant. Celery has a slightly spicy taste and a distinctive aroma so that it is widely used as a seasoning in various food products [2]. The distinctive aroma of celery comes from phthalide derivatives. Phthalides are known to have anti-inflammatory, antitumor, and insecticide properties. About $74.6-76.6 \%$ of phthalides were found in the leaves, the stem part was $56.8-74.1 \%$, and the root part was $57.7-79.7 \%$ [4].

Based on the explanation above, it can be concluded that exercise can overcome dysmenorrhea. Because exercise is safer to use because it uses a physiological process. The one-way exercise/exercises to reduce the intensity of menstrual pain is to do abdominal stretching exercise.

According to Thermacare [5], abdominal stretching exercise is a muscle stretching exercise, especially on the stomach which is done for $10 \mathrm{~min}$. This exercise is specifically designed to increase muscle strength, endurance, and flexibility so that it is expected to reduce menstrual pain and also the use of natural diuretics, such as celery leaves, watermelon can overcome dysmenorrhea. The use of this natural diuretic also has the effect of relaxing the muscles so that stomach cramps during menstruation become limp.

Based on the above background, the researchers are interested to know the effect of celery therapy and abdominal stretching exercise on the intensity of pain in adolescents with dysmenorrhea. In a study combined celery therapy and abdominal stretching exercise, so the purpose of this study was to determine the effect of celery therapy and abdominal stretching exercise on pain intensity in adolescents with dysmenorrhea in Soppeng Senior High School in 2019. The results of this study are expected to overcome menstrual pain in adolescents by doing celery therapy and abdominal stretching exercise.

\section{Materials and Methods}

The study was conducted at SMAN 1 Watan Soppeng. This research uses quasi-experimental with the matching only pre-posttest control group design.

The population in this study were all students who experienced menstrual pain (primary dysmenorrhea) who attended SMAN 1 Watan Soppeng. A sample of 30 was selected by consecutive sampling that met inclusion criteria aged 14-17 years and was willing to sign an informed consent that had been issued by the Ethics Committee of the Faculty of Public Health, Hasanuddin University.

Data collection in this study was carried out by the researchers themselves by distributing questionnaires or interviewing respondents during the pre-test and post-test. The measuring instrument used is the numeric rating scale (NRS) measurement tool. NRS is one of the standard measurement tools in assessing the level of dysmenorrhea pain.

Intervensi celery therapy and abdominal stretching exercise performed 3 days before menstruation and then post-test after the $1^{\text {st }}$ day of menstruation. Data are processed using STATA to assess the effect of celery therapy and abdominal stretching exercise using a paired $t$-test.

\section{Results}

Based on the results of the study, Table 1 shows that the average age of respondents was 14-15 years by $16(53.3 \%)$. Based on grade level, the average respondent in class one also had details of 16 (53.3\%).

Table 1: Characteristics of respondents before therapy in Soppeng district high school in 2019

\begin{tabular}{ll}
\hline Characteristics of respondents & Intervention of respondents \\
\hline Age & \\
$14-15$ years & $16(53.3 \%)$ \\
$16-17$ years old & $14(46.7 \%)$ \\
Class & \\
One & $16(53.3 \%)$ \\
Two & $14(46.7 \%)$ \\
\hline
\end{tabular}

Respondents were given a pre-test and posttest before and after therapy intervention. Table 2 is the results of pre- and post-test obtained results that the average respondent experienced moderate pain during the pre-test with a score of $0.67(S D=0.479)$ then after 
the post-test, there was a decrease in the level of pain to mild pain with an average score averaging 0.27 $(S D=0.450)$.

Table 2: Distribution of respondents based on respondents' pain scores before and after therapy (pre-test and post-test) in Soppeng Regency in 2019

\begin{tabular}{lll}
\hline Statistical value & Pain score & \\
\cline { 2 - 3 } & Pre-test & Post-test \\
\hline Intervention group & 0 & 0 \\
Minimum & 1 & 1 \\
Maximum & 0.67 & 0.27 \\
The mean & 0.479 & 0.450 \\
Elementary school & & \\
\hline
\end{tabular}

Table 3 shows the average value of the intensity of pain before therapy celery and abdominal stretching 3 times before menstruation is 0.67 $(S D=0.479)$ and after therapy to $0.27(S D=0.450)$. Wilcoxon test results showed a significant difference between the average pain intensity before and after treatment $(p=0.001<0.05)$. Hence, it can be concluded that the administration of celery therapy and abdominal stretching exercise 3 times before menstruation can significantly reduce the intensity of pain in dysmenorrhea.

Table 3: Differences in average pain before and after therapy (pre-test and post-test) in Soppeng Regency in 2019

\begin{tabular}{lllllll}
\hline Variable & Measurement & Mean & SD & SE & $\mathrm{N}$ & p-value \\
\hline Pain score & Pre-test & 0.67 & 0.479 & 0.088 & 30 & 0.001 \\
& Post-test & 0.27 & 0.450 & 0.082 & 30 & \\
\hline
\end{tabular}

\section{Discussion}

The results found that celery therapy and abdominal stretching exercise proved effective in reducing the intensity of pain in adolescents with dysmenorrhea. Researchers have not found any related research that reveals the relationship between celery therapy and abdominal stretching exercise on menstrual pain intensity, so researchers try to link celery therapy and abdominal stretching exercise one by one.

According to Asep and Ria [6], one of the nonpharmacological therapies, namely, herbal therapy which is often used for traditional medicine by the community is celery (Apium graveolens L.). Celery (A. graveolens L.) has antirheumatic, sedative, mild diuretic, and antiseptic effects on the urinary tract. From the results of the previous studies, it was reported that celery plants ( $A$. graveolens L.) contain compounds containing terpenoids and flavonoids. The previous studies proved that flavonoids have activities as antiatherosclerosis, anti-inflammatory, and antihypertensive antioxidants.

Celery is known as a vegetable supplement. However, based on the results of pharmacological analysis, it was found that almost all parts of the plant have medicinal properties. Celery roots are efficacious as a diuretic, menstrual decay, and schematic. One of the compounds contained in celery and can be used as a reliever is apigenin. The ease in getting and applying it in everyday life support celery for use in traditional alternative medicine [6].

Exercise is one of the safernon-pharmacological management to use because it uses physiological processes and one way to relieve dysmenorrhea is to do exercise. The results of the study are supported by Daley opinion [3] which states that exercise is effective in reducing menstrual pain (primary dysmenorrhea). Abdominal stretching exercise that is done during dysmenorrhea to improve the development of body awareness, reduce muscle tension (cramps), reduce muscle pain, and reduce pain during menstruation (dysmenorrhea), increase muscle strength, endurance, and muscle flexibility, can increase fitness, optimize the ability to catch, and improve mental and physical relaxation so that it is expected to reduce menstrual pain (dysmenorrhea) in women.

The research conducted by Shahr-Jerdy etal. [7] of 179 young women aged 15-17 years. Research conducted to look at the effectiveness of stretching on primary dysmenorrhea found that after 8 weeks of training, the intensity of pain decreased significantly from 7.65 to 4.88 ( $p<0.05$ ) in the intervention group.

The researchers concluded that stretching was effective in reducing pain intensity, duration of pain, and the number of pain relief tablets in adolescent girls who experience primary dysmenorrhea. Abdominal stretching exercise stimulates the body to release endorphins produced in the brain and spinal cord. Endorphin levels produced can increase 4-5 times in the blood. The more we do exercise the higher the endorphin levels. This increase in endorphins is associated with decreased pain, blood pressure, breathing, and appetite. Endorphin is a hormone that functions as a natural sedative and causes a sense of comfort. When the body exercises, endorphins come out and are captured by receptors in the hypothalamus and limbic system that function to regulate emotions [7].

Jhamb et al. [8] stated that physical exercise has a significant relationship with a decrease in the level of muscle fatigue. Adolescents with dysmenorrhea will experience muscle cramps, especially in the lower abdomen, that are cyclic due to strong and long contractions in the uterine wall resulting in muscle fatigue and physical inactivity so exercise is needed to eliminate these muscle cramps.

This is in line with research conducted by Mahvash et al. [9] of 50 students with moderate-tosevere dysmenorrhea. The results of the study found that physical activity for 8 weeks effectively reduced the type and amount of pain medication consumed by respondents, reducing the duration of pain and the intensity of dysmenorrhea pain. Muscle stretching or stretching exercises can also avoid pain that occurs in the neck, shoulders, and back and improve posture. The 
purpose of muscle stretching exercises is to help increase oxygenation or the process of oxygen and carbohydrate exchange in cells and stimulate drainage flow of the lymph system, so as to increase muscle flexibility by restoring muscles to their natural length and can maintain their function properly and improve elasticity or flexibility of body tissue and reduce muscle cramps [10-12].

However, the results of this study are not supported by the results of Blakey et al. [13] study which states that there is no relationship between dysmenorrhea with exercise/physical exercise. This study also explains that smaller studies (<500 respondents) are more likely to produce positive relationships.

The results of this study researchers can conclude that the reliever package consisting of celery therapy and abdominal stretching exercise is an easy, inexpensive, and physiological intervention. Both of these therapies reduce uterine contractions, reduce cramps in the lower abdomen, and accelerate blood circulation so that ultimately can reduce the intensity of pain in adolescents with dysmenorrhea.

\section{Conclusion}

Based on the results of research and hypotheses, it can be concluded that there are significant differences after therapy which means that the administration of celery therapy and abdominal stretching exercise 3 times before menstruation is more effective in reducing pain.

\section{References}

1. Arifin S. Nyeri Haid. Jakarta: EGC; 2008.

2. Kallo VD. Hubungan tingkat stress dengan kejadian dismenorea primer pada mahasiswi fakultas kedokteran universitas sam ratulangi manado. E J Nurs. 2012;3(2):2-6. https://doi. org/10.35790/ecl.3.1.2015.6750

3. Daley AJ. Exercise and primary dysmenorrhoea Sports Med. 2008;38(8):659-70. https://doi. org/10.2165/00007256-200838080-00004

4. Sellami IH, Bettaieb I, Bourgou S, Dahmani R, Limam F, Marzouk B. Essential oil and aroma composition of leaves, stalks and roots of celery (Apium graveolens var. dulce) from Tunisia. J Essent Oil Res. 2012;24(6):513-21. https://doi.org/10 $.1080 / 10412905.2012 .728093$

5. Thermacare. Abdominal Stretching Exercises for Menstrual Pain; 2010. Available from: http://www.chiromax.com/Media/ abstretch.pdf. [Last accessed on 2020 Jan 2020].

6. Asep S, RiaA. Celery (Apium graveolens $\mathrm{L}$ ) as a chemopreventive agent for cancer. Majority J. 2016;5(2):95-100.

7. Shahr-Jerdy S, Hosseini RS, Eivazi GH. Effects of stretching exercises on primary dysmenorrhea in adolescent girls. Biomed Hum Kinet. 2012;4(1):127-32. https://doi.org/10.2478/ v10101-012-0024-y

8. Jhamb M, Weisbord SD, Steel JL, Unruh M. Fatigue in patients receiving maintenance dialysis: A review of definitions, measures, and contributing factors. Am J Kidney Dis. 2008;52(2):353-65. https://doi.org/10.1053/j.ajkd.2008.05.005 PMid: 18572290

9. Mahvash N, Eidy A, Mehdi K, Zahra MT, Mani M, Shahla H. The effect of physical activity on primary dysmenorrhea of female university students. World Appl Sci J. 2012;17(10):1246-52.

10. Syam A, Palutturi S, Djafar N, Budu, Astuti N, Thaha AR. Micronutrients, academic performance and concentration of study: A literature review. Int J Appl Bus Econ Res. 2016;14(5):2831-43. https://doi.org/10.5455/ ijmsph.2017.10062016596

11. Birawida $A B$, Selomo $M$, Mallongi $A$. Potential hazards from hygiene, sanitation and bacterium of refill drinking water at Barrang Lompo island (water and food safety perspective). IOP Conf Earth Environ Sci. 2018;157(1):012034. https://doi. org/10.1088/1755-1315/157/1/012034

12. Mallongi $A$, Parkpian $P$, Pataranawat $P$, Chinwetkitvanich $S$. Mercury distribution and its potential environmental and health risks in aquatic habitat at artisanal buladu gold mine in Gorontalo Province, Indonesia. Pak J Nutr. 2015;14(12):1010-25. https:// doi.org/10.3923/pjn.2015.1010.1025

13. Blakey H, Chisholm C, Dear F, Harris B, Hartwell R, Daley AJ, et al. Is exercise associated with primary dysmenorrhoea in young women? BJOG. 2010;117(2):222-4. https://doi. org/10.1111/j.1471-0528.2009.02220.x

PMid:19459861 